\title{
Morphological and compositional changes in the skeletons of new coral recruits reared in acidified seawater: Insights into the biomineralization response to ocean acidification
}

\author{
Anne L. Cohen and Daniel C. McCorkle \\ Woods Hole Oceanographic Institution, Woods Hole, Massachusetts 02543, USA \\ (acohen@whoi.edu)
}

\section{Samantha de Putron}

Bermuda Institute of Ocean Sciences, Saint George's GE 01, Bermuda

\author{
Glenn A. Gaetani and Kathryn A. Rose \\ Woods Hole Oceanographic Institution, Woods Hole, Massachusetts 02543, USA
}

[1] We reared primary polyps (new recruits) of the common Atlantic golf ball coral Favia fragum for 8 days at $25^{\circ} \mathrm{C}$ in seawater with aragonite saturation states ranging from ambient $(\Omega=3.71)$ to strongly undersaturated $(\Omega=0.22)$. Aragonite was accreted by all corals, even those reared in strongly undersaturated seawater. However, significant delays, in both the initiation of calcification and subsequent growth of the primary corallite, occurred in corals reared in treatment tanks relative to those grown at ambient conditions. In addition, we observed progressive changes in the size, shape, orientation, and composition of the aragonite crystals used to build the skeleton. With increasing acidification, densely packed bundles of fine aragonite needles gave way to a disordered aggregate of highly faceted rhombs. The $\mathrm{Sr} / \mathrm{Ca}$ ratios of the crystals, measured by SIMS ion microprobe, increased by $13 \%$, and $\mathrm{Mg} / \mathrm{Ca}$ ratios decreased by $45 \%$. By comparing these variations in elemental ratios with results from Rayleigh fractionation calculations, we show that the observed changes in crystal morphology and composition are consistent with a $>80 \%$ decrease in the amount of aragonite precipitated by the corals from each "batch" of calcifying fluid. This suggests that the saturation state of fluid within the isolated calcifying compartment, while maintained by the coral at levels well above that of the external seawater, decreased systematically and significantly as the saturation state of the external seawater decreased. The inability of the corals in acidified treatments to achieve the levels of calcifying fluid supersaturation that drive rapid crystal growth could reflect a limit in the amount of energy available for the proton pumping required for calcification. If so, then the future impact of ocean acidification on tropical coral ecosystems may depend on the ability of individuals or species to overcome this limitation and achieve the levels of calcifying fluid supersaturation required to ensure rapid growth.

Components: 7568 words, 8 figures, 1 table.

Keywords: ocean acidification; coral; $\mathrm{Sr} / \mathrm{Ca}$; calcification; $\mathrm{Mg} / \mathrm{Ca}$; biomineralization.

Index Terms: 0419 Biogeosciences: Biomineralization; 4916 Paleoceanography: Corals (4220).

Received 29 January 2009; Revised 26 May 2009; Accepted 8 June 2009; Published 24 July 2009. 
Cohen, A. L., D. C. McCorkle, S. de Putron, G. A. Gaetani, and K. A. Rose (2009), Morphological and compositional changes in the skeletons of new coral recruits reared in acidified seawater: Insights into the biomineralization response to ocean acidification, Geochem. Geophys. Geosyst., 10, Q07005, doi:10.1029/2009GC002411.

\section{Introduction}

[2] The rising concentration of $\mathrm{CO}_{2}$ in Earth's atmosphere is changing the carbonate chemistry of the ocean [Orr et al., 2005]. As $\mathrm{CO}_{2}$ levels continue to rise over the next century, the surface water carbonate ion concentration $\left(\left[\mathrm{CO}_{3}^{2-}\right]\right)$ is expected to decrease by almost $50 \%$ relative to preindustrial levels [Feely et al., 2004]. In laboratory studies, multiple taxa of marine calcifying organisms exhibit high sensitivity to changes in seawater $\left[\mathrm{CO}_{3}^{2-}\right]$. The response of tropical corals is particularly well documented: under controlled experimental conditions, their calcification rates show a roughly linear decline with decreasing seawater $\left[\mathrm{CO}_{3}^{2-}\right]$ [e.g., Langdon and Atkinson, 2005]. These observations have significant implications for the survival of tropical coral reef ecosystems, but our predictive capabilities are limited by a lack of understanding of the pathways by which seawater saturation state affects coral calcification.

[3] Physicochemical models for accretion of coral skeleton typically invoke precipitation of aragonite from modified seawater within an extracellular calcifying compartment, sandwiched between the base of the tissue and either the substrate or the tip of existing skeleton. Inherent in these models is that the $\left[\mathrm{CO}_{3}^{2-}\right]$ of seawater in the coral's calcifying region [Braun and Erez, 2004] is actively elevated above typical oceanic saturation states, thus facilitating crystal nucleation and growth. This could be achieved with plasma membrane $\mathrm{Ca}^{2+}$-ATPase, an obligatory $\mathrm{Ca}^{2+}-\mathrm{H}^{+}$exchanger [Zoccola et al., 2004] that removes two $\mathrm{H}^{+}$ions for every $\mathrm{Ca}$ ion transported into the calcifying space, a process that can quickly and effectively elevate fluid saturation significantly above that of ambient seawater. Although direct measurements of the saturation state of fluid within the calcifying space (the so-called "calcifying fluid") have not been made, in situ measurements of the calcifying fluid $\mathrm{pH}$ imply that $\left[\mathrm{CO}_{3}^{2-}\right]$ within the calcifying space during lightenhanced calcification may be at least as high as $1200 \mu \mathrm{molkg}^{-1}$, five times higher than that of ambient seawater [Al-Horani et al., 2003]. Under such conditions, aragonite precipitation is rapid
[Burton and Walter, 1987], allowing the coral to build a sturdy skeleton of densely packed bundles of fine aragonite needles. However, despite this evidence that calcification occurs at significantly elevated aragonite saturation states, calcification appears to be strongly sensitive to very small changes in the saturation state of the external seawater environment. For example, mature colonies reared over a period of weeks in seawater with a $10 \%$ reduction in $\left[\mathrm{CO}_{3}^{2-}\right]$ exhibited a $50 \%$ reduction in calcification [Langdon et al., 2000]. The results of this and subsequent studies have fueled concern over the future plight of coral reefs and the ecosystems they support under increasing anthropogenic $\mathrm{CO}_{2}$ in the atmosphere [Kleypas et al., 2006].

[4] To examine the mechanism whereby changes in seawater $\left[\mathrm{CO}_{3}^{2-}\right]$ influences coral calcification, we tracked early skeletal development by new recruits (spat) of the brooding coral Favia fragum at $25^{\circ} \mathrm{C}$ and four saturation states for a period of 8 days postsettlement. Early calcification involves initiation of skeletogenesis by a previously noncalcifying planktonic planula (coral larva), and therefore offers a unique opportunity to precisely pinpoint the timing of aragonite formation and the subsequent development of skeletal components under a range of conditions. Further, because all skeletal accretion occurs during the experiment, observed changes in the morphology and chemistry of harvested crystals among different treatments can be linked directly with manipulated changes in aquarium conditions.

[5] Normal development of the primary skeleton starts with deposition, directly onto the substrate, of radiating arrays of fine aragonite crystals that fuse to form a thin, circular plate (basal plate) [Vandermeulen and Watabe, 1973; Le Tissier, 1988]. Desmoid processes anchor the tissue to the plate [Le Tissier, 1988], and later, as the sides of the plate are built upward into a shallow bowl, it may serve to seal the calcifying space from the external seawater environment, enabling the coral polyp to effectively elevate the saturation state of the calcifying fluid to achieve rapid calcification. Subsequent accretion of skeletal components of the 


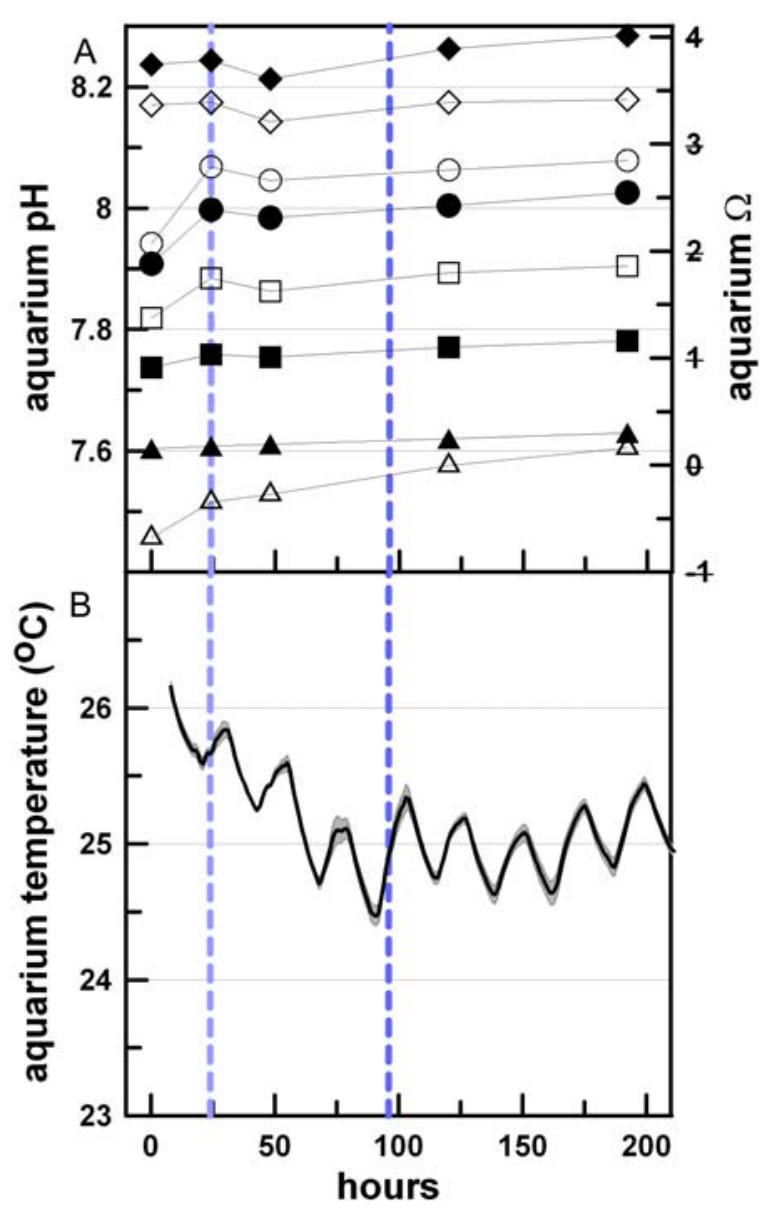

Figure 1. Tank conditions. (a) The pH(NBS) (solid symbols) and seawater saturation state with respect to aragonite ( $\Omega$, open symbols) measured in the experimental aquaria over the course of the experiment. (b) Average seawater temperatures logged in the four experimental aquaria over the course of the experiment. Error bars are the $1 \sigma$ standard error. Vertical broken lines indicate when, during the course of the experiment, the settled larvae were introduced into the aquaria (light blue) and when aragonite was first detected on harvested tiles from the control tank (dark blue).

corallite (the primary and secondary septa, the corallite wall and columella) occurs above the basal plate [Le Tissier, 1988]. These components are built of dense bundles of fine $(<1 \mu$ m diameter) aragonite fibers which are also the building blocks of the adult skeleton [e.g., Wells, 1956; Constantz, 1989; Gladfelter, 1983]. The early initiation of calcification and rapid subsequent growth of these skeletal components which support, protect and elevate the tissue from the substrate, are crucial steps in the successful recruitment and survival of coral spat [Babcock and Mundy, 1996; Zilberberg and Edmunds, 2001].

\section{Experimental and Analytical Methods}

[6] Gravid colonies of $F$. fragum were collected from the Bermudian reef and placed in covered outdoor flow-through aquaria where they released mature worm-like planula larvae over several days starting 22 July 2007. Larvae were transferred within $6 \mathrm{~h}$ to small $(0.251)$ plastic settlement containers filled with ambient and acidified seawater from the experimental aquaria (see below) and containing preconditioned ceramic tiles. Preconditioning was achieved by leaving the tiles on racks on nearby reefs for 4-6 weeks to obtain the necessary biofilms and algae to induce settlement. Within $24 \mathrm{~h}$ following the first release, approximately $80 \%$ of the previously motile larvae had settled onto the tiles and metamorphosed into a doughnut-shaped primary polyp, approximately $1 \mathrm{~mm}$ in diameter and firmly attached to the substrate. The tiles, each hosting $30-45$ primary polyps, were immediately transferred to static, $30 \mathrm{~L}$ aquaria containing unfiltered reef seawater preadjusted via $\mathrm{HCl}$ addition to alkalinity values of $2421 \pm 74,1862 \pm 50,1181 \pm 55$, and $506 \pm$ $118 \mathrm{ueq} / \mathrm{kg}$, and set by continuous bubbling with laboratory air, yielding carbonate ion concentrations of $238 \pm 16,154 \pm 8,67 \pm 10$, and $14 \pm 7$, corresponding to aragonite saturation states of: $\Omega=3.71 \pm 0.23$ (unmodified), $\Omega=2.40 \pm 0.11, \Omega=$ $1.03 \pm 0.16$, and $\Omega=0.22 \pm 0.11$ (Figure 1a). The zooxanthellate primary polyps were reared in the aquaria for 8 days, at an average water temperature of $25^{\circ} \mathrm{C}$ (Figure $1 \mathrm{~b}$ ) on a $12 \mathrm{~h} / 12 \mathrm{~h}$ light/dark cycle and light levels $61 \pm 6 \mu \mathrm{Em}^{-2} \mathrm{~s}^{-1}$. The timing of skeletal development was checked by successive harvesting of sets of tiles followed by immersion for several hours in a $10 \%$ sodium chlorite solution diluted with reef seawater. All remaining tiles were harvested after 8 days.

[7] Water samples were collected from the aquaria at the beginning and end of the experiment, and poisoned immediately after collection. Alkalinity (Alk) and dissolved inorganic carbon (DIC) were measured using a closed cell titration on $\sim 100 \mathrm{~mL}$ samples, standardized using certified reference materials obtained from Dr. A Dickson (SIO); the precision of the titrations was $\pm 0.2 \%$ for both alkalinity and DIC in ambient seawater, but only $\pm 0.6 \%$ and $\pm 1.7 \%$ (Alk and DIC, respectively) in 
the most strongly acidified treatment. This resulted in an uncertainty in calculated saturation state of roughly $\pm 0.5 \%$ at ambient conditions and $\pm 16 \%$ in the lowest $\Omega$ treatment. In addition, $\mathrm{pH}$ in each aquarium was monitored daily using a Radiometer combination electrode; the $\mathrm{pH}_{(\mathrm{NBS})}$ values were $8.17 \pm 0.006,8.04 \pm 0.03,7.87 \pm 0.015$ and $7.54 \pm$ 0.02 , consistent with values calculated from the large-volume titrations.

[8] The small size of the larval corals prohibited direct measurement of calcification rate by alkalinity anomaly or buoyant weight methods. To estimate the extent of skeletal development in each treatment, we quantified both the cross-sectional area and weight of the primary and secondary septa, and when developed, the columella within each corallite. Cross-sectional area was obtained by photographing each 8-day-old corallite and using image histogram and photographic software tools $\left(\right.$ Photoshop ${ }^{\mathbb{R}}$ ) to estimate the total area of skeleton visible in the photograph. Corallite weights, a more direct measure of the amount of aragonite accreted by each polyp during the experiment, were obtained by removing all visible skeleton, excluding the basal plate, from a minimum of five corallites on each tile using a $0.5 \mathrm{~mm}$ fine forceps and a fine brush. The skeletal components were weighed on a Mettler-Toledo microbalance, then mounted in epoxy, polished and prepared for element ratio analysis by secondary ion mass spectrometry (SIMS). A Cameca 3 f ion microprobe employing a $\sim 4 \mathrm{nA}$ primary $\mathrm{O}^{-}$beam, $20 \mu \mathrm{m}$ in diameter and accelerated at $12.5 \mathrm{keV}$ was used for all element ratio analyses. Following a $3 \mathrm{~min}$ preburn to remove the $\mathrm{Au}$ coat, a single spot was occupied while measuring secondary ion intensities for ${ }^{24} \mathrm{Mg},{ }^{42} \mathrm{Ca}$, and ${ }^{88} \mathrm{Sr}$ within a $30 \mathrm{eV}$ window centered on an $80 \mathrm{eV}$ offset from the peak of the energy distribution. This energy filtering reduces molecular interferences to $<0.1 \%$ [Hart and Cohen, 1996]. The mass spectra for $\mathrm{Mg}, \mathrm{Ca}$, and $\mathrm{Sr}$ were determined to be free from significant isobaric interferences through a comparison of measured isotope ratios with natural abundances. Isotope ratios were converted to molar ratios using working curves constructed from three carbonate standards: a carbonatite crystal (OKA), a calcite crystal (0875) and an aragonite crystal (AG1) with $\mathrm{Mg} / \mathrm{Ca}$ ratios of $0.27-4.47 \mathrm{mmol} / \mathrm{mol}$ and $\mathrm{Sr} / \mathrm{Ca}$ ratios of $0.56-19.3 \mathrm{mmol} / \mathrm{mol}$. The composition of each standard was determined by solution ICP-MS [Holcomb et al., 2009]. Routine instrument preci- sion for ${ }^{24} \mathrm{Mg} /{ }^{42} \mathrm{Ca}$ and ${ }^{88} \mathrm{Sr} /{ }^{42} \mathrm{Ca}$ are $1.2 \%$ and $0.3 \%$, respectively.

\section{Acid Addition Versus $\mathrm{pCO}_{2}$ Manipulation}

[9] In this study, seawater $\left[\mathrm{CO}_{3}^{2-}\right]$ was manipulated by $\mathrm{HCl}$ addition rather than by $\mathrm{CO}_{2}$ enrichment, which would be more similar to the global uptake of fossil fuel $\mathrm{CO}_{2}$ by the oceans. There is a fundamental chemical difference between these two approaches that could, in theory, influence the calcification response, depending on both the biomineralization mechanism involved and the availability of an alternative source of dissolved inorganic carbon (DIC) for calcification. While data from our companion $\mathrm{pCO}_{2}$ experiments with new coral recruits indicate that the calcification response is identical whether $\mathrm{HCl}$ or $\mathrm{CO}_{2}$ is used to manipulate seawater saturation state (S. de Putron et al., manuscript in preparation, 2009), it is worthwhile to clarify the differences between these two techniques.

[10] Manipulation of seawater $\left[\mathrm{CO}_{3}^{2-}\right]$ by elevating the $\mathrm{pCO}_{2}$ of the aquarium seawater increases the dissolved inorganic carbon concentration (DIC) and bicarbonate concentration $\left[\mathrm{HCO}_{3}^{-}\right]$of the solution. In contrast, addition of $\mathrm{HCl}$ lowers the alkalinity of the aquarium seawater. In our experiment, the $\mathrm{pCO}_{2}$ of the low-alkalinity seawater was then set by bubbling with laboratory air $\left(\mathrm{pCO}_{2}\right.$ $\sim 450 \mathrm{ppm}$ ). The resulting equilibrium DIC and $\left[\mathrm{HCO}_{3}^{-}\right]$concentrations are substantially lower than in the initial seawater, and much lower than in seawater where the same low initial $\left[\mathrm{CO}_{3}^{2-}\right]$ has been achieved by $\mathrm{CO}_{2}$ enrichment. If an organism calcifies by modifying the chemistry of a small volume of seawater-derived calcifying fluid, and if no DIC is added to this calcifying fluid during the calcification process, then no matter how much energy the organism expends to increase the $\mathrm{pH}$ of the calcifying fluid by removing protons, the final $\left[\mathrm{CO}_{3}^{2-}\right]$ of that fluid can never be pushed above its initial DIC concentration. This places a relatively low upper limit on the potential saturation state of the calcifying fluid in acid addition experiments (Figure 2a). In contrast, if the experimental saturation state is lowered by $\mathrm{pCO}_{2}$ enrichment, then the $\left[\mathrm{CO}_{3}^{2-}\right]$ and saturation state of the calcifying fluid can reach much higher values (Figure 2b). The calculations shown in Figure 2 are for an idealized, closed system calcifying space with no DIC addition. However, if sufficient metabolic $\mathrm{CO}_{2}$ is available for calcification, then the corals in acid 
addition experiments may not experience the closed system DIC limitation seen in Figure 2a. Such DIC addition could happen, for example, because of diffusion of metabolic $\mathrm{CO}_{2}$ into the calcifying region as the $\mathrm{pH}$ of the calcifying fluid increases and its $\mathrm{pCO}_{2}$ drops, as proposed by McConnaughey and Falk [1991] and Cohen and McConnaughey [2003]. Indeed, results from at least three studies suggest that DIC addition to the site of calcification is likely. First, data published by Furla et al. [2000] indicate that metabolic $\mathrm{CO}_{2}$ is likely a significant source of DIC for calcification in zooxanthellate corals. Second, in a direct comparison of different saturation state manipulation methods, Schneider and Erez [2006] did not observe any limitation to calcification arising from acid addition. And finally, our own data from recent $\mathrm{CO}_{2}$ enrichment experiments with Favia and Porites new recruits, in which we elevated $\mathrm{pCO}_{2}$ to produce external saturation states as low as $\Omega=1.4$, show reductions in calcification comparable to the reductions seen in our acid

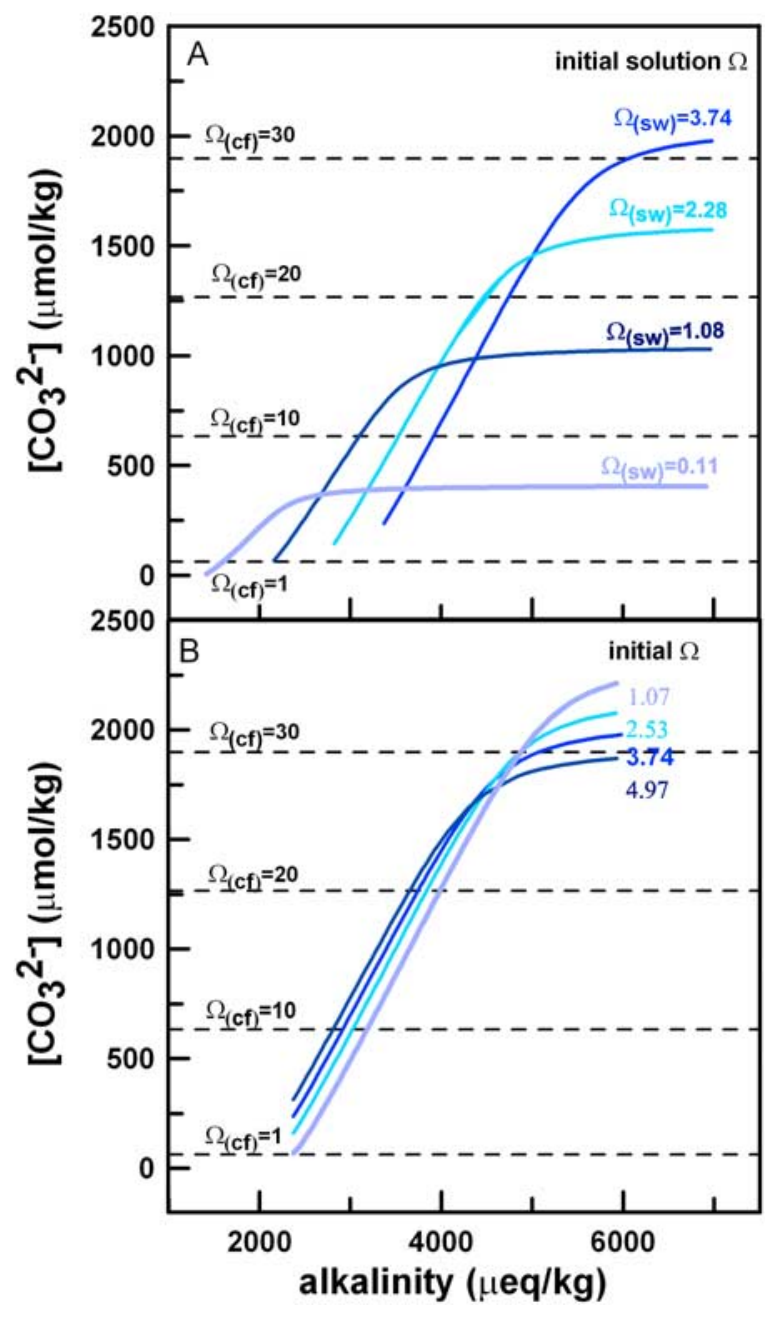

addition experiments with similar saturation states (S. de Putron et al., manuscript in preparation, 2009).

\section{Results}

[11] Aragonite was accreted by corals in all treatments, including those reared under strongly undersaturated conditions (Figure 3). In the ambient tanks, aragonite was first detected on the tiles approximately 3 days after settlement. However, in the $\Omega=1.04$ and $\Omega=0.22$ treatments, aragonite was first detected on the tiles between 4 and 5 days after settlement, and subsequent skeletal development was visibly depressed. The shape of the basal plate, circular under normal conditions (Figure 3a), became increasingly distorted with decreasing saturation state, possibly reflecting anatomical distortions of the basal disc (Figures $3 \mathrm{c}$ and $3 \mathrm{~d}$ ). In the strongly undersaturated seawater $(\Omega=0.22)$, basal plates, if present, were ill defined and lacked a well-developed rim. This combination may have made it difficult for the primary polyps to effectively seal the calcifying region from the external seawater, contributing both to the delay in onset of

Figure 2. Model calculations of the carbonate ion concentration in the calcifying fluid as a function of calcifying fluid alkalinity illustrate the potential for DIC limitation when solution carbonate chemistry is manipulated by (a) acid addition rather than by (b) $\mathrm{CO}_{2}$ enrichment. The increase in alkalinity ( $x$ axis) is equal to proton removal from the calcifying space by the coral. All calculations were carried out using a spreadsheet implementation of the CO2SYS program of Lewis and Wallace [1998], with the dissociation constants of Roy et al. [1993]. In both sets of calculations the DIC of the calcifying fluid (cf) was held at the concentration in the appropriate aquarium, and salinity (36.8 psu) and temperature $\left(27^{\circ} \mathrm{C}\right)$ were held constant (values are hypothetical and do not exactly match conditions in our experimental aquaria). In Figure 2a, when solution saturation state is set by acid additions at fixed initial $\mathrm{pCO}_{2}$, low- $\Omega$ treatments have low initial alkalinity and DIC concentrations. The maximum carbonate ion concentration (and thus the maximum saturation state) that can be attained can be no higher than the DIC initially present in the solution (asymptotic values of the curves). In Figure $2 b$, this potential limitation does not occur when solution $\Omega$ is lowered by $\mathrm{CO}_{2}$ enrichment: high- $\mathrm{pCO}_{2}$ (low- $\Omega$ ) treatments have high initial DIC concentrations, and thus higher maximum carbonate ion concentrations. The initial DIC will still place an upper limit on the final $\Omega$, assuming no DIC addition to the calcifying fluid, but these asymptotic $\Omega$ values are much higher than in acid addition experiments. 


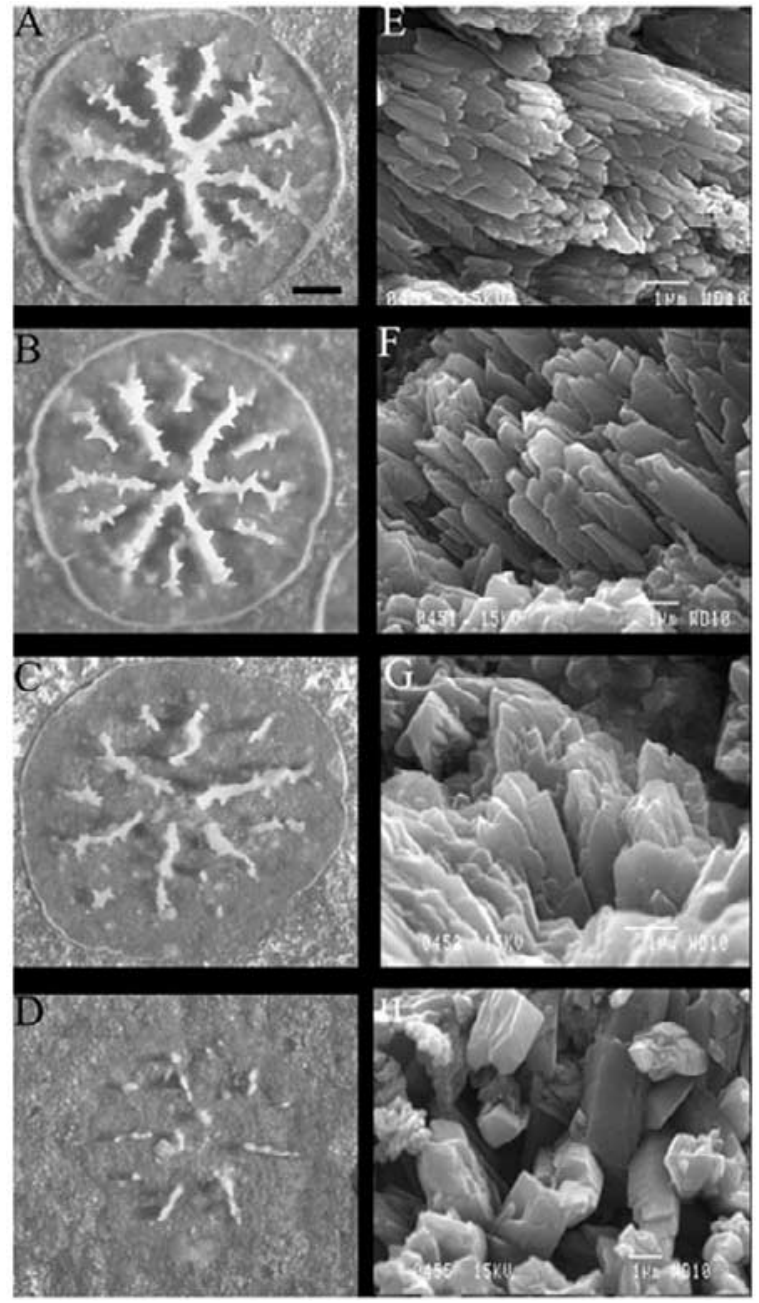

Figure 3. $(a-d)$ Progressive changes in the mesoscale skeletal development, including distortion of basal plate and retardation of septal development, of 8-day-old corallites of Favia fragum with decreasing seawater saturation state. Visible changes in the amount of aragonite produced by the corals are quantified by cross-sectional area analysis and weighing of individual corallites (see Figure 5). (e-h) Progressive changes in the morphology and orientation of crystals within the corallites are documented by scanning electron microscopy imaging of broken faces of primary septa. In Figures $3 \mathrm{a}$ and $3 \mathrm{e}, \Omega=3.71$ (control); in Figures $3 \mathrm{~b}$ and 3f, $\Omega=2.40$; in Figures $3 \mathrm{c}$ and $3 \mathrm{~g}, \Omega=1.03$; and in Figures $3 \mathrm{~d}$ and $3 \mathrm{~h}, \Omega=0.22$. In Figure $3 \mathrm{a}$, scale bar is $200 \mu \mathrm{m}$.

skeletogenesis and to the reduction in growth rate once calcification was initiated.

[12] Raman spectroscopy identified all crystals precipitated by the larval corals as aragonite, even in the strongly undersaturated seawater experiment $(\Omega=0.22)$. However, Scanning Electron Microscope (SEM) images of broken faces of septa show that morphological features of the aragonite crystals vary systematically with changing saturation state of the aquarium seawater (Figures $3 \mathrm{e}-3 \mathrm{~h}$ ). Crystals in the control skeletons (precipitated at $\Omega=3.71$ ) were long, thin blades, the long or $\mathrm{c}$ axis of each crystal oriented in parallel with its neighboring crystals, and organized into discrete densely packed bundles that are characteristic of corals in the wild [e.g., Wells, 1956; Constantz, 1989; Gladfelter, 1983] (Figure 3e). As the saturation state of the external seawater decreased, crystals became shorter and thicker, their orientation became increasingly random, and the discrete fiber bundles disappeared. Crystals accreted in the lowest saturation state experiments $(\Omega=0.22)$ were highly faceted rhombs rather than fine blades (Figure 3h). The minimal skeleton built of these crystals lacked the ordered microstructure of skeleton grown at ambient conditions, and crumbled to the touch (Figures $4 a$ and $4 b$ ).

[13] Visible changes in the mesoscale skeletal development were quantified using both the cross-sectional area of skeletal deposits and the average corallite weight (Figure 5). The crosssectional area of skeleton deposited by primary polyps in seawater with moderately lowered saturation state $(\Omega=2.40)$ was more than $20 \%$ less than the control, and in strongly undersaturated seawater $(\Omega=0.22)$, skeletal development was $75 \%$ less than the control. The average weight of skeletal elements in each corallite was reduced by $26 \%$ at $\Omega=2.40$ and by $95 \%$ at $\Omega=0.22$.

[14] Average $\mathrm{Mg} / \mathrm{Ca}$ and $\mathrm{Sr} / \mathrm{Ca}$ ratios of skeleton accreted by corals at ambient conditions are $6.6 \pm$ $0.4 \mathrm{mmol} / \mathrm{mol}$ and $9.8 \pm 0.3 \mathrm{mmol} / \mathrm{mol}$, respectively, similar to that measured in the skeletons of adult Bermudan Diploria labyrinthiformis by SIMS ion microprobe [Gaetani and Cohen, 2006] (Table 1 and Figure 6). However, a systematic change in skeletal composition occurred with changing seawater saturation state, despite the strictly isothermal conditions. Average $\mathrm{Mg} / \mathrm{Ca}$ ratios of the skeletons reared at constant and equivalent temperature decrease by $45 \%$, from $6.6 \pm 0.4 \mathrm{mmol} / \mathrm{mol}$ to $3.6 \pm 0.5 \mathrm{mmol} / \mathrm{mol}$, and average $\mathrm{Sr} / \mathrm{Ca}$ ratios increase by $13 \%$, from $9.8 \pm 0.3 \mathrm{mmol} / \mathrm{mol}$ to $11.2 \pm$ 0.3 , as the saturation state of seawater in the tanks decreased from $\Omega=3.71$ to $\Omega=0.22$.

\section{Discussion}

[15] Recently there has been a great deal of interest in the possibility that changes in the saturation state 

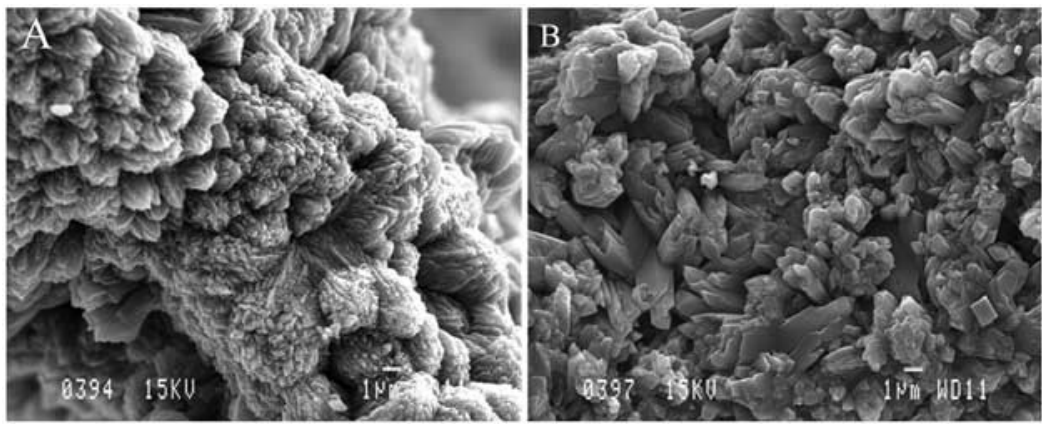

Figure 4. (a) Skeleton accreted by the corals under ambient conditions $(\Omega=3.71)$ consists of organized bundles of fine (submicron) fibers, as do the skeletons of corals grown in the wild. As the saturation state of the aquarium seawater decreased, the morphology and arrangement of crystals changed. (b) In the lowest saturation state treatment $(\Omega=0.22)$ the minimal skeleton accreted consisted of a disordered aggregate of highly faceted rhombs.

of the oceans, caused by increasing levels of atmospheric $\mathrm{CO}_{2}$, may impact the ability of marine calcifying organisms to build their shells and skeletons. Experimental and field studies of a wide range of marine calcifying taxa suggest that calcification by many, although not all, organisms studied [Iglesias-Rodriguez et al., 2008; J. Ries et al., Marine calcifiers exhibit mixed response to $\mathrm{CO}_{2}$-induced ocean acidification, submitted to Geology, 2009] is strongly dependent on seawater saturation state $(\Omega)$. The negative impact of decreasing $\Omega$ on calcification by the scleractinian corals is well documented in several studies of mature colonies and at least one study of juveniles [Albright et al., 2008]. Experimental studies using both $\mathrm{HCl}$ and $\mathrm{pCO}_{2}$ [e.g., Schneider and Erez, 2006] show that coral calcification responds similarly to both methods of $\left[\mathrm{CO}_{3}^{2-}\right]$ manipulation. While the sensitivity of calcification to changes in $\Omega$ differs among different studies, many experiments to date report between $40 \%$ and $60 \%$ decline in calcification with a $10 \%$ drop in $\Omega$ (as summarized by Langdon and Atkinson [2005]). This strong sensitivity of coral calcification to very small changes in seawater saturation state raises questions about the nature of the linkages between coral biomineralization processes and conditions in the external seawater environment.

[16] Evidence based on in situ microelectrode measurements of calcifying fluid $\mathrm{pH}$ [Al-Horani et al., 2003] as well as the chemistry and morphology of aragonite crystals that make up the coral skeleton [Holcomb et al., 2009] suggests that, under normal conditions, corals elevate the saturation state of fluid within the calcifying compartment as much as 7 times above that of the ambient seawater in order to precipitate aragonite. Therefore, it is not immediately obvious why coral calcification, which occurs in a compartment that is isolated from the external environment, should respond so strongly to changes in seawater $\left[\mathrm{CO}_{3}^{2-}\right]$ much smaller than the changes incurred by the organism itself. A mechanistic understanding of the coral calcification response to ocean acidification is therefore critical to predicting how different species on different reefs experiencing multiple, dif-
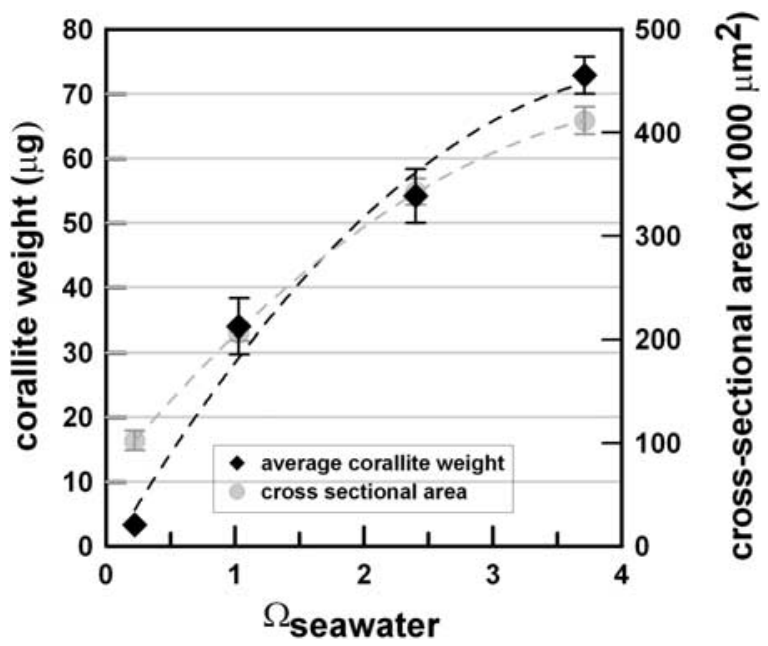

Figure 5. Average corallite size (cross-sectional area) and weight of aragonite precipitated by the new coral recruits in the experimental aquaria. The cross-sectional area of corallites was estimated in Photoshop ${ }^{\mathbb{B}}$ by selecting all skeletal components above the basal plate (i.e., including primary and secondary septa and columella if present) and using the histogram tool to quantify the cross-sectional area. Weights were obtained by removing the entire corallite, including the basal plate if present, from the tile using a pair of fine forceps and a fine brush. A minimum of five corallites were used for each weight estimate. Error bars are the $1 \sigma$ standard error. 
Table 1. Average $\mathrm{Mg} / \mathrm{Ca}$ and $\mathrm{Sr} / \mathrm{Ca}$ Ratios of Aragonite Accreted by New Favia fragum Recruits Reared in $25^{\circ} \mathrm{C}$ Seawater Over a Range of Aragonite Saturation States ${ }^{\mathrm{a}}$

\begin{tabular}{ccccc}
\hline$\Omega_{\text {seawater }}$ & $\begin{array}{c}\mathrm{Mg} / \mathrm{Ca} \\
(\mathrm{mmol} / \mathrm{mol})\end{array}$ & $\begin{array}{c}\text { Standard } \\
\text { Error }\end{array}$ & $\begin{array}{c}\mathrm{Sr} / \mathrm{Ca} \\
(\mathrm{mmol} / \mathrm{mol})\end{array}$ & $\begin{array}{c}\text { Standard } \\
\text { Error }\end{array}$ \\
\hline 3.71 & 6.567 & 0.387 & 9.771 & 0.283 \\
2.40 & 6.214 & 0.273 & 9.841 & 0.178 \\
1.03 & 5.058 & 0.220 & 10.469 & 0.251 \\
0.22 & 3.624 & 0.482 & 11.223 & 0.319 \\
\hline
\end{tabular}

${ }^{a}$ Element ratios were generated by in situ Secondary Ion Mass Spectrometric (ion microprobe) analyses of aragonite from 5 corallites in each experiment. The standard error is the standard deviation divided by the square root of $n$.

ferent stressors will respond to global environmental change over the next century.

[17] In this study, skeletal accretion by juvenile corals reared from the larval stage in experimental aquaria showed a strong response to changes in seawater saturation state induced by $\mathrm{HCl}$ addition and continuous bubbling with laboratory air. Initiation of calcification was delayed and subsequent growth was visibly depressed in the treatment tanks relative to the control. On the basis of measurements of the amount of aragonite accreted by polyps over the study period, an approximately $18 \%$ drop in calcification occurred per unit drop in seawater saturation state. This sensitivity is consistent with that reported for other zooxanthellate scleractinia in experimental and field studies [Langdon and Atkinson, 2005].

[18] Our results demonstrate that corals are able to accrete aragonite even under strongly undersaturated conditions, attesting to the extent of organismal control over conditions within the calcifying compartment. This observation contrasts with results from most experiments with mature coral colonies, in which calcification was not detected below saturation states of $\sim 1$ (see review by Langdon and Atkinson [2005]). Nevertheless, in the young coral skeletons, changes in crystal morphology were apparent long before $\Omega_{\text {aragonite }}$ dropped below 1. As the saturation state of the experimental seawater decreased from $\Omega=3.71$ to $\Omega=2.40$, aragonite needles within each fiber bundle became visibly shorter and wider, and as $\Omega$ approached 1, the integrity of the fiber bundles was lost altogether. Under strongly undersaturated conditions, the densely packed bundles of fine needles characteristic of a normal skeleton gave way to randomly oriented highly faceted rhombs.
[19] Similar, systematic changes have been observed in the morphology of carbonates precipitated from seawater at varying aragonite supersaturations [Holcomb et al., 2009] and in silicate minerals grown from a silicate melt at varying undercoolings, which is analogous to supersaturation [e.g., Lofgren, 1971, 1980]. In aragonites precipitated experimentally from seawater at $25^{\circ} \mathrm{C}$, Holcomb et al. [2009] found that dense, closed spherulites containing long, thin blades of aragonite precipitated from the seawater solution when the saturation state was relatively high $(\Omega \sim 25)$, whereas coarse open spherulites containing highly faceted crystals precipitated when the saturation state was relatively low $(\Omega \sim 6)$. This suggests a change in the growth kinetics of the crystals in response to the changing saturation state of the solution from which they grew. In general, the higher the precipitation rate, the greater the departure of the crystal form from the equilibrium shape [Burton et al., 1951; Keith and Padden, 1963; Lofgren, 1971, 1980]. In aragonites, this means a shift from the equilibrium orthorhombic shape to long, thin blades. Using the abiogenic aragonites as a framework for interpreting morphological changes observed in the coral crystals, we suggest that the observed changes in the coral skeleton reflect changes in the saturation state of the coral's calcifying fluid. This in turn implies that as the saturation state of seawater in the experimental

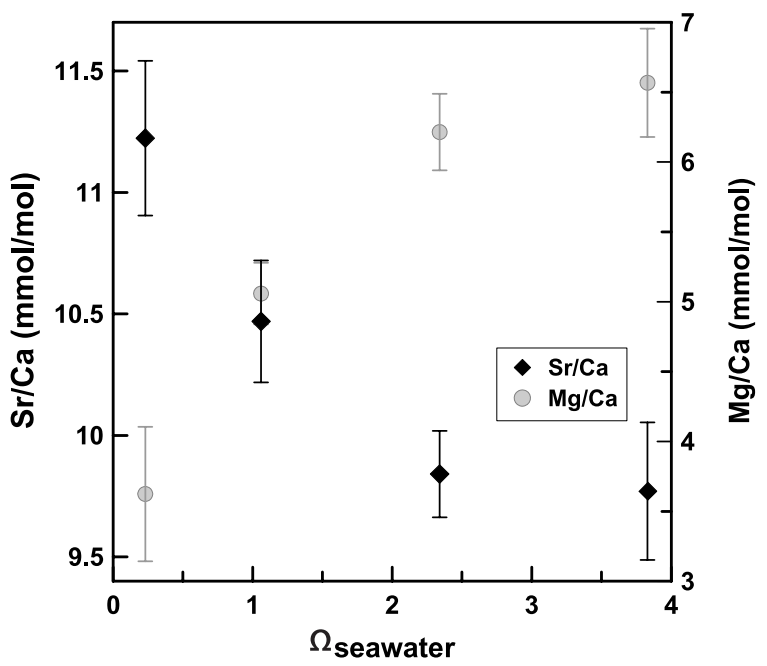

Figure 6. $\mathrm{Sr} / \mathrm{Ca}$ (solid diamonds) and $\mathrm{Mg} / \mathrm{Ca}$ (gray circles) ratios of aragonite accreted by the new coral recruits in the four experimental aquaria as a function of the saturation state of the seawater in which the corals were reared (see Table 1). Data were generated by SIMS ion microprobe analyses of septa; each point is the mean value of five analyses. The error bars are the $1 \sigma$ standard error. 


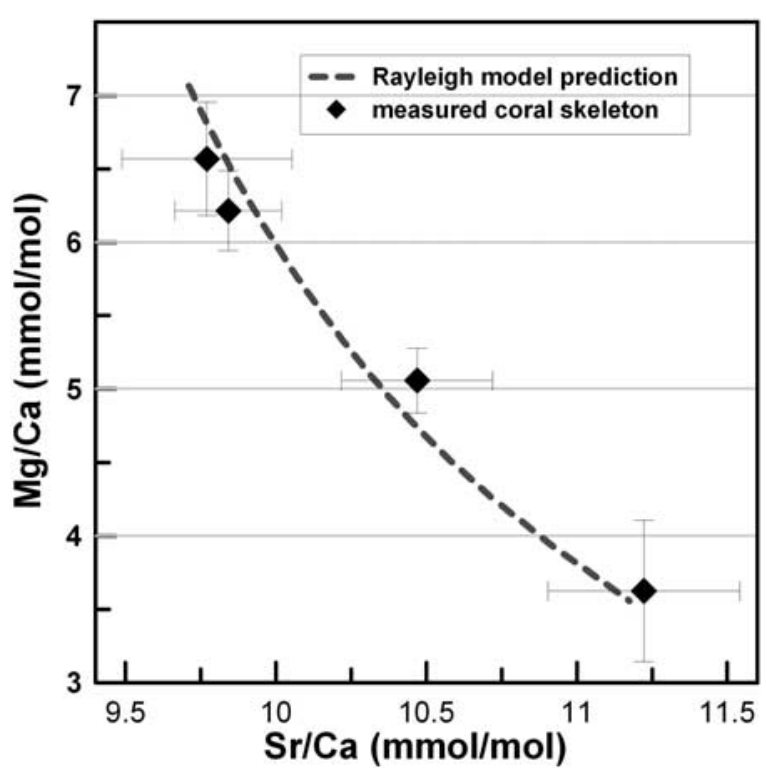

Figure 7. Variations in elemental ratios $(\mathrm{Mg} / \mathrm{Ca}$ and $\mathrm{Sr} / \mathrm{Ca}$ ) (see Table 1) of skeleton accreted by new coral recruits in the experimental aquaria (solid diamonds) compared with results from Rayleigh fractionation calculations (dashed line) (see Appendix A). The Rayleigh distillation equation (1) [Rayleigh, 1896] relates the average concentration of an element $i$ in the aragonite $\left(\bar{C}_{i}^{\text {Aragonite }}\right)$ to its concentration in the calcifying fluid as precipitation begins $\left(C_{i}^{0}\right)$, the mass fraction of the initial fluid remaining at a given point during aragonite precipitation $(F L)$, and the Nernst aragonite-seawater partition coefficient for element $i\left(D_{i}^{\text {Aragonite-Seawater }}\right)$. The Rayleigh equation accurately predicts the coral composition when the mass fraction of aragonite precipitated by the corals (1-FL in equation (1)) decreases from $0.07 \%$ to $<0.01 \%$ as the aragonite saturation state of seawater in the tanks drops from $\Omega=3.71$ to $\Omega=0.22$.

aquaria decreased, the saturation state of the coral's internal calcifying fluid also decreased.

[20] Systematic changes in the $\mathrm{Sr} / \mathrm{Ca}$ and $\mathrm{Mg} / \mathrm{Ca}$ ratios of the coral skeletons provide further insight into the mechanism by which changes in seawater saturation state affect coral calcification. As seawater saturation state decreased in the experimental aquaria, $\mathrm{Sr} / \mathrm{Ca}$ ratios of the skeletons increased by $13 \%$ and $\mathrm{Mg} / \mathrm{Ca}$ ratios decreased by $45 \%$. Both the trend and the relative magnitude of changes in $\mathrm{Sr} / \mathrm{Ca}$ and $\mathrm{Mg} / \mathrm{Ca}$ ratios are consistent with a Rayleigh distillation process in which compositional variability in the coral skeleton is driven primarily by changes in the mass fraction of aragonite precipitated by the coral from an isolated "batch" or reservoir of calcifying fluid (hereafter referred to as the "mass fraction") [Gaetani and Cohen, 2006; Cohen et al., 2006; Gagnon et al., 2007]. The data were modeled using the following solution to the Rayleigh distillation equation [Rayleigh, 1896]:

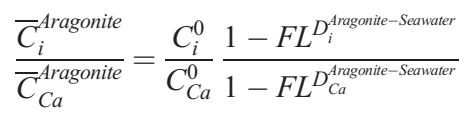

where $\bar{C}_{i}^{\text {Aragonite }}$ is the average concentration of element $i$ in the aragonite, $C_{i}^{0}$ is the concentration of element $i$ in the calcifying fluid as precipitation begins, FL the mass fraction of the initial fluid remaining at a given point during aragonite precipitation, and $D_{i}^{\text {Aragonite-Seawater }}$ is the Nernst aragonite-seawater partition coefficient for element $i$. In this study, the known variables are the composition of the aragonite $\left(\bar{C}_{i}^{\text {Aragonite }}\right)$ and the Nernst aragonite-seawater partition coefficients $\left(D_{i}^{\text {Aragonite-Seawater }}\right)$ which were derived independently from abiogenic aragonite precipitated from seawater at controlled growth rates [Gabitov et al., 2006] (Appendix A). A global minimization was carried out to solve equation (1) for the mass fraction of aragonite precipitated from each batch of calcifying fluid (1-FL), the initial composition of the calcifying fluid $\left(C_{i}^{0}\right)$ and the growth rate of the crystals (see Appendix A).

[21] In Figure 7, we compare the measured variations in elemental ratios with results from our Rayleigh fractionation calculations. The results from our calculations show that the compositional variability observed in the coral skeletons can be explained by variations in the mass fraction of aragonite (1-FL) precipitated by the corals from each batch of calcifying fluid brought into the calcifying space. The results from our calculations also indicate that the mass of aragonite precipitated decreased from $\sim 0.07 \%$ of the initial mass of a batch of calcifying fluid to $<0.001 \%$ as the saturation state of the aquarium seawater decreases from $\Omega=3.71$ to $\Omega=0.22$. This corresponds to roughly $70 \%$ and $0.1 \%$ of the $\mathrm{Ca}^{2+}$ initially present in the calcifying fluid. The results from our calculations also indicate that crystal growth rates decreased by $\sim 30 \%$ between the ambient and strongly undersaturated seawater treatments and that in all the experiments, regardless of seawater saturation state, the $\mathrm{Mg} / \mathrm{Ca}$ and $\mathrm{Sr} / \mathrm{Ca}$ ratios of the coral's calcifying fluid at the start of precipitation were very close to seawater values $(5.3 \mathrm{~mol} / \mathrm{mol}$ and $8.9 \mathrm{mmol} / \mathrm{mol}$, respectively).

[22] In Figure 8, we compare the mass fraction aragonite precipitated by the corals as predicted by the Rayleigh model with the actual weight of the corallites as a function of the saturation state of the 


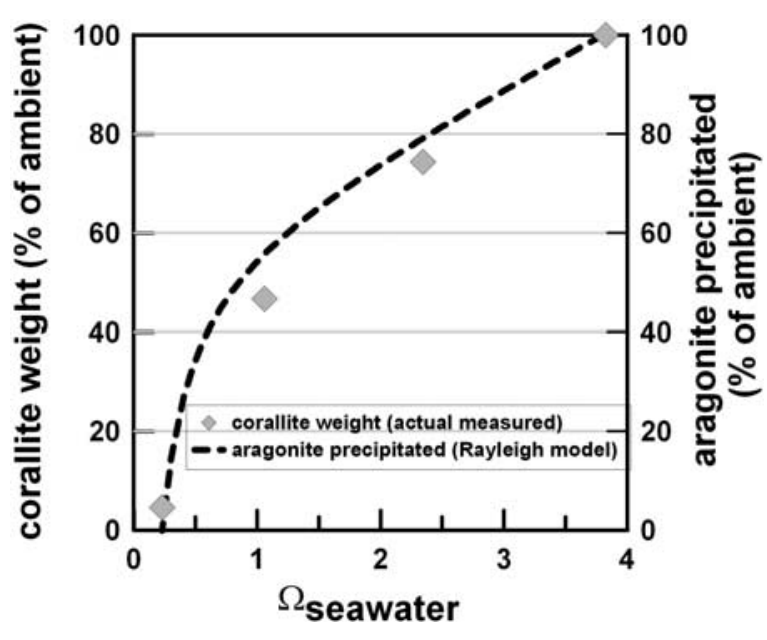

Figure 8. The mass fraction aragonite precipitated by the primary polyps as predicted by the Rayleigh calculations, compared with the actual weight of the corallites as a function of the aragonite saturation state of the aquarium seawater. Both parameters are expressed as a percentage of the ambient. Corallite weight and percent aragonite precipitated at ambient $\Omega$ are set at $100 \%$.

aquarium seawater. Although coral calcification rate depends on both the mass fraction of aragonite precipitated and the rate at which the calcifying fluid is replenished in the calcifying compartment, our data indicate that at least in these juvenile corals, the amount of skeleton produced by each corallite over the 8 day period is closely related to the mass fraction of aragonite precipitated from each batch of calcifying fluid.

[23] Accretion of aragonite even in strongly undersaturated seawater demonstrates that the coral elevates the saturation state of the calcifying fluid significantly above that of the external seawater. So, how do changes in the saturation state of seawater cause large changes in the saturation state of the calcifying fluid? One possibility is that primary polyps of Favia fragum have a limited ability to raise the saturation state of the seawater brought into their calcifying space, reflecting either a limit to the amount of energy available for proton pumping, or a more fundamental limit to the rate of proton pumping regardless of the polyp's energy budget. In either case, as the aragonite saturation state of the external seawater drops, the polyp's ability to raise the saturation state of the calcifying fluid decreases, and leads to aragonite precipitation at lower rates than are necessary to build an orderly skeleton of fine fiber bundles.

[24] The IPCC business-as-usual emissions scenario A2 predicts that the saturation state of the midlatitude surface oceans could drop by almost $50 \%$ by 2100 A.D. [Caldeira and Wickett, 2005]. If this happens our data suggest that, unless corals can increase the rate of proton pumping, possibly by diverting more energy to this task, a significant drop in the rate of skeleton building by new coral recruits could occur over the next century, and by 2300 A.D., rates of early calcification could be too slow to sustain growth of a normal skeleton.

\section{Appendix A}

[25] The $\mathrm{Mg} / \mathrm{Ca}$ and $\mathrm{Sr} / \mathrm{Ca}$ ratios of aragonite precipitated from an isolated reservoir of calcifying fluid are described by a solution to the Rayleigh distillation equation [Rayleigh, 1896]:

$$
\frac{\bar{C}_{i}^{\text {Aragonite }}}{\bar{C}_{C a}^{\text {Aragonite }}}=\frac{C_{i}^{0}}{C_{C a}^{0}} \frac{1-F L^{D_{i}^{\text {Aragonite-Senvaler }}}}{1-F L^{D_{C a}^{\text {Aragonite-Senvater }}}}
$$

where $\bar{C}_{i}^{\text {Aragonite }}$ is the average concentration of element $i$ in the aragonite, $C_{i}^{0}$ is the concentration of element $i$ in the calcifying fluid as precipitation begins, $F L$ is the mass fraction of the initial fluid remaining at any point during aragonite precipitation, and $D_{i}^{\text {Aragonite-Seawater }}$ is the Nernst aragoniteseawater partition coefficient for element $i$. Kinetics exerts the principal control on element distribution during carbonate precipitation at low temperatures, so that partition coefficients vary with crystal growth rate [Lorens, 1981; Watson, 2004; Gaetani and Cohen, 2006; Gabitov et al., 2008]. Gabitov et al. [2006] carried out abiogenic precipitation experiments at $25^{\circ} \mathrm{C}$ and determined the partitioning of $\mathrm{Mg}, \mathrm{Sr}$ and $\mathrm{Ca}$ between aragonite and seawater at linear crystal growth rates of 2.7-117 $\mu \mathrm{m} / \mathrm{d}$. Results from these experiments were fit to a logarithmic functional form to derive expressions that describe growth rate-dependent partitioning:

$$
\begin{aligned}
& C_{M g}^{\text {Aragonite }} / C_{M g}^{\text {Seawater }}=0.2616 \times \ln (r)+0.2882 \mathrm{r}^{2}=0.9199 \\
& C_{S r}^{\text {Aragonite }} / C_{S r}^{\text {Seawater }}=275.2 \times \ln (r)+1423.99 \mathrm{r}^{2}=0.9051 \\
& C_{C a}^{\text {Aragonite }} / C_{C a}^{\text {Seawater }}=191.2 \times \ln (r)+1237.78 \mathrm{r}^{2}=0.8693
\end{aligned}
$$

where $\mathrm{C}$ is weight concentration and $r$ is crystal growth rate in microns per day. 
[26] Calculations were carried out as follows. First, equations describing the growth rate-dependent partitioning of $\mathrm{Mg}, \mathrm{Sr}$ and $\mathrm{Ca}$ between aragonite and seawater (equations (A2)-(A4)) were substituted into equation (A1) to derive a growth ratedependent Rayleigh equation for each elemental ratio obtained by analyzing the coral skeleton. The concentrations of $\mathrm{Mg}$ and $\mathrm{Sr}$ in the calcifying fluid were treated as unknowns, and normalized to a $\mathrm{Ca}$ concentration of $394 \mathrm{ppm}$. Elemental ratios in the calcifying fluid at the beginning of precipitation were assumed to be independent of seawater saturation state. In order to avoid local minima, functional forms were assumed for the relationships between saturation state $(\Omega)$ and FL or $r$. Global minimization calculations resulted in the following empirical relationships:

$$
\begin{gathered}
F L=0.9996-8.34 \times 10^{-5} \Omega+8.57 \times 10^{-5} \Omega^{-1} \\
r=68.52 \Omega^{0.11}
\end{gathered}
$$

A simple polynomial was used to describe the relationship between FL and $\Omega$ because our current understanding of coral biomineralization does not provide a theoretical basis for predicting the functional form. The functional form of the relationship between $\mathrm{r}$ and $\Omega$ was taken from the empirical rate equation [e.g., Mucci and Morse, 1983; Burton and Walter, 1987], except that saturation state was used in place of supersaturation. Because the actual saturation state of the calcifying fluid is unknown, coefficients derived from fitting our data to this equation do not have the same physical significance as would be the case for controlled precipitation experiments.

[27] Combining equations (A1)-(A6) results in a series of independent equations that are mathematically overconstrained: each of the $4 \mathrm{Sr} / \mathrm{Ca}$ and $\mathrm{Mg} / \mathrm{Ca}$ ratios (averaged from 5 analyses of coral per treatment) provides 2 known quantities $(\mathrm{Mg} / \mathrm{Ca}$ and $\mathrm{Sr} / \mathrm{Ca}$ ratios) for a total of $2 \times 4=8$ constraints, and the unknown quantities are the $\mathrm{Mg} / \mathrm{Ca}$ and $\mathrm{Sr} / \mathrm{Ca}$ ratios of the calcifying fluid at the onset of precipitation, and coefficients for equations relating FL and $r$ to $\Omega$, for a total of 7 . The minimized quantity was the sum of the squared percentage difference between the measured ratios and those predicted by the Rayleigh model:

$$
\sum\left(100 \times\left(i / C a_{\text {Rayleigh }}-i / C a_{\text {Measured }}\right) / i / C a_{\text {Measured }}\right)^{2}
$$

where $i / C a_{\text {Rayleigh }}$ and $i / C a_{\text {Measured }}$ are the elementto-calcium ratio predicted by the Rayleigh equation and measured in the coral skeleton, respectively.

\section{Acknowledgments}

[28] The authors are grateful for technical assistance from Louis Kerr (Scanning Electron Microscopy), Nobuchimi Shimizu (Secondary Ion Mass Spectrometery), and Rebecca Belastock (Alk/DIC analyses) and for the constructive comments of reviewers which greatly improved the manuscript. This study was supported by NSF OCE-0648157 and NSF OCE-0823527 and the Bermuda Institute for Ocean Sciences.

\section{References}

Albright, R., B. Mason, and C. Langdon (2008), Effect of aragonite saturation state on settlement and post-settlement growth of Porites astreoides larvae, Coral Reefs, 27, 485-490, doi:10.1007/s00338-008-0392-5.

Al-Horani, F. A., S. M. Al-Moghrabi, and D. de Beer (2003), The mechanism of calcification and its relation to photosynthesis and respiration in the scleractinian coral Galaxea fascicularis, Mar. Biol. Berlin, 142, 419-426.

Babcock, R. C., and C. Mundy (1996), Coral recruitment: Consequences of settlement choice for early growth and survivorship in two scleractinians, J. Exp. Mar. Biol. Ecol., 206, 179-201, doi:10.1016/S0022-0981(96)02622-6.

Braun, A., and J. Erez (2004), Preliminary observations on sea water utilization during calcification in scleractinian corals, Eos Trans. AGU, 85(47), Fall Meet. Suppl., Abstract B14B-04.

Burton, E. A., and L. M. Walter (1987), Relative precipitation rates of aragonite and $\mathrm{Mg}$ calcite from seawater: Temperature or carbonate ion control?, Geology, 15, 111-114, doi:10.1130/0091-7613(1987)15<111:RPROAA>2.0.CO;2.

Burton, W. K., N. Cabrera, and F. C. Frank (1951), The growth of crystals and the equilibrium structure of their surfaces, Philos. Trans. R. Soc. London, Ser. A, 243, 299-358.

Caldeira, K., and M. E. Wickett (2005), Ocean model predictions of chemistry changes from carbon dioxide emissions to the atmosphere and ocean, J. Geophys. Res., 110, C09S04, doi:10.1029/2004JC002671.

Cohen, A. L., and T. A. McConnaughey (2003), A geochemical perspective on coral mineralization, in Biomineralization, Rev. in Mineral. Geochem., vol. 54, edited by P. M. Dove, S. Weiner, and J. J. deYoreo, pp. 151-187, Mineral. Soc. of Am., Washington, D. C.

Cohen, A. L., G. A. Gaetani, T. Lundälv, B. H. Corliss, and R. Y. George (2006), Compositional variability in a coldwater scleractinian, Lophelia pertusa: New insights into "vital effects," Geochem. Geophys. Geosyst., 7, Q12004, doi:10.1029/2006GC001354.

Constantz, B. R. (1989), Skeletal organisation in Acropora, in Origin, Evolution and Modern Aspects of Biomineralization in Plants and Animals, edited by R. E. Crick, pp. 175-200, Plenum, New York.

Feely, R. A., C. L. Sabine, K. Lee, W. Berelson, J. Kleypas, V. J. Fabry, and F. J. Millero (2004), Impact of anthropogenic $\mathrm{CO}_{2}$ on the $\mathrm{CaCO}_{3}$ system in the oceans, Science, 305, 362-366, doi:10.1126/science.1097329.

Furla, P., I. Galgani, I. Durand, and D. Allemand (2000), Sources and mechanisms of inorganic carbon transport for 
coral calcification and photosynthesis, J. Exp. Biol., 203, 3445-3457.

Gabitov, R. I., A. L. Cohen, G. A. Gaetani, and M. Holcomb (2006), Growth rate dependence of $\mathrm{Mg}$, Sr, and U incorporation into aragonite: Experimental constraints on the origin of vital effects, Eos Trans. AGU, 87(52), Fall Meet. Suppl., Abstract B13B-1076.

Gabitov, R. I., G. A. Gaetani, E. B. Watson, A. L. Cohen, and H. L. Ehrlich (2008), Experimental determination of growth rate effect on $\mathrm{U}^{6+}$ and $\mathrm{Mg}^{2+}$ partitioning between aragonite and fluid at elevated $\mathrm{U}^{6+}$ concentration, Geochim. Cosmochim. Acta, 72, 4058-4068, doi:10.1016/j.gca.2008.05.047.

Gaetani, G. A., and A. L. Cohen (2006), Element partitioning during precipitation of aragonite from seawater: A framework for understanding paleoproxies, Geochim. Cosmochim. Acta, 70, 4617-4634, doi:10.1016/j.gca.2006.07.008.

Gagnon, A. C., J. F. Adkins, D. P. Fernandez, and L. F. Robinson (2007), $\mathrm{Sr} / \mathrm{Ca}$ and $\mathrm{Mg} / \mathrm{Ca}$ vital effects correlated with skeletal architecture in a scleractinian deep-sea coral and the role of Rayleigh fractionation, Earth Planet. Sci. Lett., 261, 280-295, doi:10.1016/j.eps1.2007.07.013.

Gladfelter, E. H. (1983), Skeletal development in Acropora cervicornis. Diel patterns of calcium carbonate accretion, Coral Reefs, 2, 91-100, doi:10.1007/BF02395279.

Hart, S. R., and A. L. Cohen (1996), An ion probe study of annual cycles of $\mathrm{Sr} / \mathrm{Ca}$ and other trace elements in corals, Geochim. Cosmochim. Acta, 60, 3075-3084, doi:10.1016/ 0016-7037(96)00154-8.

Holcomb, M., A. L. Cohen, R. I. Gabitov, and J. L. Hutter (2009), Compositional and morphological features of aragonite precipitated experimentally from seawater and biogenically by corals, Geochim. Cosmochim. Acta, 73, 4166-4179, doi:10.1016/j.gca.2009.04.015.

Iglesias-Rodriguez, M. D., et al. (2008), Phytoplankton calcification in a high- $\mathrm{CO}_{2}$ world, Science, 320, 336-340, doi:10.1126/science.1154122.

Keith, H. D., and F. J. Padden (1963), A phenomological theory of spherulitic crystallization, J. Appl. Phys., 34, 2409-2421, doi:10.1063/1.1702757.

Kleypas, J. A., R. A. Feely, V. J. Fabry, C. Langdon, C. L. Sabine, and L. L. Robbins (2006), Impacts of ocean acidification on coral reefs and other marine calcifiers: A guide for future research, report, 88 pp., Natl. Sci. Found., Arlington, Va.

Langdon, C., and M. J. Atkinson (2005), Effect of elevated $\mathrm{pCO}_{2}$ on photosynthesis and calcification of corals and interactions with seasonal change in temperature/irradiance and nutrient enrichment, J. Geophys. Res., 110, C09S07, doi:10.1029/2004JC002576.

Langdon, C., T. Takahashi, C. Sweeney, D. Chipman, J. Goddard, F. Marubini, H. Aceves, H. Barnett, and M. J. Atkinson (2000), Effect of calcium carbonate saturation state on the calcification rate of an experimental coral reef, Global Biogeochem. Cycles, 14(2), 639-654.

Le Tissier, M. D. A. (1988), Patterns of formation and the ultrastructure of the larval skeleton of Pocillopora damicornis, Mar. Biol. Berlin, 98, 493-501, doi:10.1007/BF00391540.
Lewis, E., and D. W. R. Wallace (1998), Program developed for $\mathrm{CO}_{2}$ system calculations, ORNL/CDIAC-105, Carbon Dioxide Inf. Anal. Cent., Oak Ridge Natl. Lab., U.S. Dep. of Energy, Oak Ridge, Tenn.

Lofgren, G. (1971), An experimental study of plagioclase crystal morphology: Isothermal crystallization, Am. J. Sci., 274, $243-273$

Lofgren, G. (1980), Experimental studies on the dynamic crystallization of silicate melts, in Physics of Magmatic Processes, edited by R. B. Hargraves, pp. 487-565, Princeton Univ. Press, Princeton, N. J.

Lorens, R. B. (1981), Sr, Cd, Mn and Co distribution coefficients in calcite as a function of calcite precipitation rate, Geochim. Cosmochim. Acta, 45, 553-561, doi:10.1016/ 0016-7037(81)90188-5.

McConnaughey, T. A., and R. H. Falk (1991), Calciumproton exchange during algal calcification, Biol. Bull., 180, 185-195, doi:10.2307/1542440.

Mucci, A., and J. W. Morse (1983), The incorporation of $\mathrm{Mg}^{2+}$ and $\mathrm{Sr}^{2+}$ into calcite overgrowths: Influences of growth rate and solution composition, Geochim. Cosmochim. Acta, 47, 217-233, doi:10.1016/0016-7037(83)90135-7.

Orr, J. C., et al. (2005), Anthropogenic ocean acidification over the twenty-first century and its impact on calcifying organisms, Nature, 437, 681-686, doi:10.1038/nature04095.

Rayleigh, J. W. S. (1896), Theoretical considerations respecting the separation of gases by diffusion and similar processes, Philos. Mag., 42, 77-107.

Roy, R. N., L. N. Roy, K. M. Vogel, C. Portermoore, T. Pearson, C. E. Good, F. J. Millero, and D. M. Campbell (1993), The dissociation-constants of carbonic-acid in seawater at salinities 5 to 45 and temperatures $0^{\circ} \mathrm{C}$ to $45^{\circ} \mathrm{C}$, Mar. Chem., 44, 249-267, doi:10.1016/0304-4203(93)90207-5.

Schneider, K., and J. Erez (2006), The effect of carbonate chemistry on calcification and photosynthesis in the hermatypic coral Acropora eurystoma, Limnol. Oceanogr., 51, 1284-1293.

Vandermeulen, J. H., and N. Watabe (1973), Studies on reef corals. I. Skeleton formation by newly settled planula larva of Pocillopora damicornis, Mar. Biol. Berlin, 23, 47-57, doi:10.1007/BF00394111.

Watson, E. B. (2004), A conceptual model for near-surface kinetic controls on the trace-element and stable isotope composition of abiogenic calcite crystals, Geochim. Cosmochim. Acta, 68, 1473-1488, doi:10.1016/j.gca.2003.10.003.

Wells, J. W. (1956), Scleractinia, in Treatise on Invertebrate Paleontology, part F, Coelenterata, edited by R. C. Moore, pp. F328-F479, Geol. Soc. of Am., New York.

Zilberberg, C., and P. J. Edmunds (2001), Competition among small colonies of Agaricia: The importance of size asymmetry in determining competitive outcome, Mar. Ecol. Prog. Ser., 221, 125-133, doi:10.3354/meps221125.

Zoccola, D., E. Tambutté, E. Kulhanek, S. Puverel, J. Scimeca, D. Allemand, and S. Tambutté (2004), Molecular cloning and localization of a PMCA P-type ATPase from the coral Stylophora pistillata, Biochim. Biophys. Acta, 1663, 117126, doi:10.1016/j.bbamem.2004.02.010. 